\title{
nature
}

25 September 1997 Volume 389 Issue no 6649

\section{The cloud over Sarawak}

Forest fires and urban pollution are wreaking havoc in South-East Asia. Technology and ecology can offer a little help, but more national and international awareness would also be useful.

$\mathrm{P}$ eople in the West could be excused for having missed it, but an environmental disaster has been developing in Indonesia, Malaysia and Singapore. Barely noticed by the Western media over the past two weeks, the region has been hit by atmospheric pollution at levels seriously affecting millions of people, with hundreds of deaths because of consequently impeded emergency relief from another calamity - drought. The situation is worsening as we go to press.

The calamity highlights two severe problems. One is potentially lethal smog that has arisen in urban areas due to a combination of factors - in that sense, economic progress has made unhealthy places of Kuala Lumpur and Sarawak, where vehicle and industrial pollution regularly produce dense smogs. Add to that the plumes from forest fires now raging in upwind Indonesia and it is small wonder that world pollution records are being broken (see page 321). The only silver lining on this cloud from Kalimantan and Sumatra is that it could put additional pressure on rapidly developing nations to clean up their acts.

The second problem reflected in these events is that of devastating forest management. This year, the annual burn of forest clearings in Indonesia has spread out of control largely due to the drought - itself due to the intense El Niño. Indonesia is 75 per cent (rapidly diminishing) forest which, whatever may be said to the contrary by Indonesian agencies, is poorly protected and policed in the face of destructive practices and the economic pressures that give rise to them. Indeed, there is every reason to believe that fires on this scale result from clearances partly aided by the government to promote migration, rather than slash-and-burn agriculture.

Forest clearances for the timber industry -25 per cent of the country's industrial exports - give rise to a species of broad-leaved grass that grows densely and acts like a tinderbox. Once it starts to burn, there is little anyone can do but pray for heavy rain. But experience in similar terrain in northern Australia, for example, has demonstrated the value of controlled burning: choosing the scale on which to burn, controlling spread by firebreaks and by the appropriate frequency and timing with respect to the weather. Replanting with trees to block the light and thus cut back the grassland can also be desirable.

Obstacles to such approaches in Indonesia are no doubt significant. In the long term, spreading awareness of environmental consequences is probably as substantial a contribution to solving the problem as any other. That awareness can be fostered not only by campaigns by governments but also with technology: the growing availability of remote-sensing images can assist in minimizing damage and in the appreciation of the scale of potential problems.

Attempts at international forestry agreements are constantly undermined by national pressures - as Venezuela, for example, is demonstrating in its blocking of forestry action within the United Nations biodiversity convention. Such agreements are based on the principle that forestry management is primarily a national responsibility, but the international perspective they bring — of best practice and feasible options, for example - can only help the resolve of countries in tackling such problems.

It is all the more regrettable, therefore, that international awareness is low and diminishing in developed countries which themselves contribute to forest devastation. The indifference to SouthEast Asia currently exhibited by Western media stands in marked contrast to, for example, the epic response to minor health problems among some fishermen on the east coast of the United States (see pages 317-318). Regrettably, that reflects a growing insularity in the West, both in the media and in the populations that they serve and reflect.

\section{Ashkenazi signals are timely}

\section{Concerns in the US Jewish community about the potential misuse of genetic results need to be addressed.}

$\mathrm{O}$ ne of the profound ironies of modern science is that no social group is better equipped either in its ability to provide reliable, ordered health data or in its capacity to interpret its genetic and medical implications than the Jewish community. At the same time, no group has greater reason to be wary of the way in which such implications can be misused.

That issue has now prompted some leaders of the US Jewish community to seek reassurance that research data from studies of particular ethnic groups are not used to those groups' disadvantage (see page 322). Their concern is that the publicity surrounding recent research - such as last year's discovery of a significant proportion of a particular breast cancer mutation among Ashkenazi Jews in the United States, and similar recent findings related to colon cancer may indirectly create problems for members of that group, for example in obtaining adequate health insurance cover.

Several important points need to be remembered. One is that a high incidence of a particular mutation does not necessarily imply a high incidence of the related disease; other, perhaps environmental or psychological, factors may be equally important. The second is that, for understandable reasons of research methodology, most recent genetic 'discoveries' have been associated with wellstructured - and often geographically isolated - social groups, such as the inhabitants of Tristan da Cunha (asthma), Iceland (familial essential tremor) and Finland (diastrophic dysplasia).

Unsurprisingly, the diseases chosen for study in these groups tend to be those with a significantly higher presence than in the rest of the population. But the attractiveness of searching for other genetic clues in these same populations should not blind researchers to the potential risks. The real challenge is eliminating the stigma still attached to the concept of 'mutant'. This is a question partly of education, partly of legislation (for example, banning genetic discrimination in insurance and employment). If the flag raised by the Jewish community helps to speed either process, it will have achieved a worthwhile goal. 